\title{
Genetics of production traits in Hevea brasiliensis (rubber). I. Changes in genetical control with age
}

\author{
N. E. M. JAYASEKERA, K. B. KARUNASEKERA \& M. J. KEARSEY*† \\ Rubber Research Institute, Agalawatta, Sri Lanka and $\dagger$ School of Biological Sciences, The University of Birmingham, \\ Birmingham B15 2TT, UK
}

\begin{abstract}
To determine the nature and extent of genetical and environmental control of production traits in rubber trees, nine clones were studied in replicated trials in Sri Lanka at seven sites. The clones represented a range of indigenous and imported germplasm whereas the sites were selected to represent a range of rubber growing areas. Trees were studied for two important production traits over 15 years including 9 years after the initiation of tapping for latex: girth, a measure of vigour, and rubber yield. The results of the analyses of girth data show a consistent increase in heritability over the 15 years from 12 per cent to over 75 per cent with a corresponding decrease in the effect of the environment ( 70 per cent to 12 per cent). With respect to yield, there was no such change from environmental control to genetic control of the character over the 5 years during which yield was monitored. Correlations between final tree size and earlier measurements indicate that different genes are involved in pre- and post-tapping growth. This implies that post-tapping size measurements alone are useful as predictors of final size. There are nonsignificant but negative correlations between vigour and rubber production. The implications of these findings to breeding and selection of rubber for these two production traits are discussed.
\end{abstract}

Keywords: Hevea brasiliensis, latex flow, post-tapping, pre-tapping, rubber yield, vigour.

\section{Introduction}

Rubber (Hevea brasiliensis) is the second largest plantation crop in Sri Lanka next to tea. The total extent of cultivated rubber has been estimated to be around $2 \times 10^{5}$ hectares (Anon, 1991) and the rubber industry provides employment, both directly and indirectly, to about $5 \times 10^{5}$ persons (Yogaratnam et al., 1992). Sri Lanka's total production of rubber in 1990 was $11.3 \times 10^{4}$ metric tons and the total export for the same year was $8.6 \times 10^{4}$ metric tons valued at 76.80 million US dollars (Anon, 1991).

Rubber in Sri Lanka is generally grown in wet country, mainly at altitudes below $300 \mathrm{~m}$. A certain amount of rubber is also grown in the intermediate rainfall zone (e.g. Bibile) which receives less rain restricted to one season: the north-east monsoon.

Rubber trees are grown for their latex from which rubber is coagulated and processed and hence it is the dry rubber yield which determines the level of output. Girth is an economically important character and is considered to be a measure of vigour. It determines the

\footnotetext{
*Correspondence.
}

age at which a clone could be exploited and is therefore important in shortening the uneconomic, immature period. Furthermore, large trunks have more timber value.

Yield and vigour, as measured by dry rubber content and girth respectively, are two of the three most important selection criteria in any Hevea breeding programme. The third criterion is tolerance to important foliar diseases.

Genotypic $(\mathrm{G})$, environmental $(\mathrm{E})$ and genotype $\times$ environment interaction $(\mathrm{G} \times \mathrm{E})$ are the three main components of variability in any population. The relative magnitudes of these not only determine the response to selection but also the method of selection in any breeding programme. Thus a knowledge of these components of variation is of great value to the breeders. There are no previous reports on studies of these genetical aspects of rubber although the importance of a knowledge of the adaptability of rubber clones to the diverse agro-climatic and soil conditions under which rubber is grown has been stressed (Swaminathan, 1975).

Therefore, in 1975 an experimental trial was designed to study the $\mathrm{G}, \mathrm{E}$ and $\mathrm{G} \times \mathrm{E}$ in Hevea with 
respect to the production traits, girth and rubber yield. Early height and second year yield data collected from this experiment have been analysed and reported previously (Jayasekera et al., 1977; Jayasekera \& Karunasekera, 1984).

The present paper reports results of the analysis of girth, collected over a 15-year period, and yield data, collected during the first 5 years of tapping, from this trial and shows how relative contributions of genetic, environmental and genotype $\times$ site interaction components change over time.

\section{Materials and methods}

\section{Materials}

The genetic material originally consisted of ten Hevea clones which are listed in Table 1 . They were chosen to represent a good cross-section of both local and foreign clones available at the time of establishing this trial. Some clones such as RRIC 100, PB 86 and RRIC 102 were recommended clones whereas some others had been used extensively for establishing rubber plantations in the immediate past. Most of these clones had been and were being used as parents in rubber breeding programmes in Sri Lanka. Unfortunately, one clone, RRIC 103, had to be removed from the analysis of data as it was found to be severely affected by Corynespora leaf disease.

In rubber, a budded stump, which is the planting material, consists of two parts: the rootstock and the budpatch. The rootstocks are derived from open-pollinated seedlings and hence are genetically variable. The budpatch is a vegetative part and is grafted on to the stock seedling. Since the budpatch is of clonal origin it produces the genetically uniform part of the commercial rubber tree.

\section{Environments}

The trial was located at seven different sites chosen to represent different rubber planting districts. All the sites were located on public sector estates and their detailed features are tabulated in Table 2.

\section{Field design}

A fully randomized design was used with 10 replicates (plots) per clone per site. In all sites except Bibile, which is a dry area, four plants were used in each plot. In Bibile, a larger plot size of six was used to overcome establishment difficulties. A plot consisted of four or six adjacent plants.

One and a half-year-old rootstock seedlings raised in nurseries were used to budgraft clonal materials.
Table 1 Origin of rubber clones used in the trial

\begin{tabular}{rrrcc}
\hline No. & Clone & Origin & $\begin{array}{c}\text { Mean final } \\
\text { girth }(\mathrm{cm})\end{array}$ & $\begin{array}{c}\text { Mean annual } \\
\text { yield }(\mathrm{g})^{*}\end{array}$ \\
\hline 1 & RRIC 100 & Sir Lanka & 65.8 & 29.7 \\
2 & RRIC 101 & Sri Lanka & 66.0 & 27.1 \\
3 & RRIC 102 & Sri Lanka & 69.5 & 33.4 \\
4 & RRIC 36 & Sri Lanka & 67.2 & 28.8 \\
5 & RRIC 52 & Sri Lanka & 86.1 & 25.2 \\
6 & RRIM 600 & Malaysia & 75.8 & 44.7 \\
7 & RRIM 623 & Malaysia & 78.7 & 29.4 \\
8 & IAN 45-710 South America & 80.4 & 41.2 \\
9 & PB 86 & Malaysia & 71.0 & 29.7 \\
10 & RRIC 103 & Sri Lanka & - & - \\
\hline
\end{tabular}

*Per tapping, per tree; mean of 5 years.

Budgrafting commenced on 18 July and was completed in the first week of August 1975. The successful budgrafts were uprooted and planted in the field on the dates given in Table 2 . Since the only planting season in Bibile was the north-east monsoon period, the other sites were also planted in this season, although normally the south-west monsoon would be their main planting season.

Plants were spaced at $6.09 \mathrm{~m}\left(20^{\prime}\right)$ between rows and $3.65 \mathrm{~m}\left(12^{\prime}\right)$ within the row. The trial sites were fertilized with NPK mixture and magnesium in the form of dolomite, applied according to the recommendations of the Rubber Research Institute (Silva, 1972; Yogaratnam, 1984a,b). Missing plants were replaced with spares during the first 2 years after planting to maintain the plantation density but were not scored.

\section{Measurements}

Vigour, in terms of girth (circumference in $\mathrm{cm}$ ), was measured annually from the date of planting. During the first 2 years diameter measurements were recorded, because plants were too small to measure the girth, and converted to girth assuming that the stem was cylindrical. Pre-tapping and post-tapping girth measurements were taken at $91.4 \mathrm{~cm}\left(3^{\prime}\right)$ and $152.4 \mathrm{~cm}$ $\left(5^{\prime}\right)$ above the highest point of the bud union, respectively.

Trees that reached a girth of $45.7 \mathrm{~cm}\left(18^{\prime \prime}\right)$ or more were opened for tapping at a height of $106.6 \mathrm{~cm}\left(42^{\prime \prime}\right)$ above the bud union. Tapping started towards the end of 1982 and from the beginning of 1983. Attempts were made to record one yield measurement (test tapping) per month for each site.

Yield was recorded on the days when normal tapping, which starts around $6.30 \mathrm{Am}$, was possible. After tapping, latex was allowed to collect in plastic cups provided for each recording tree. Once the latex 

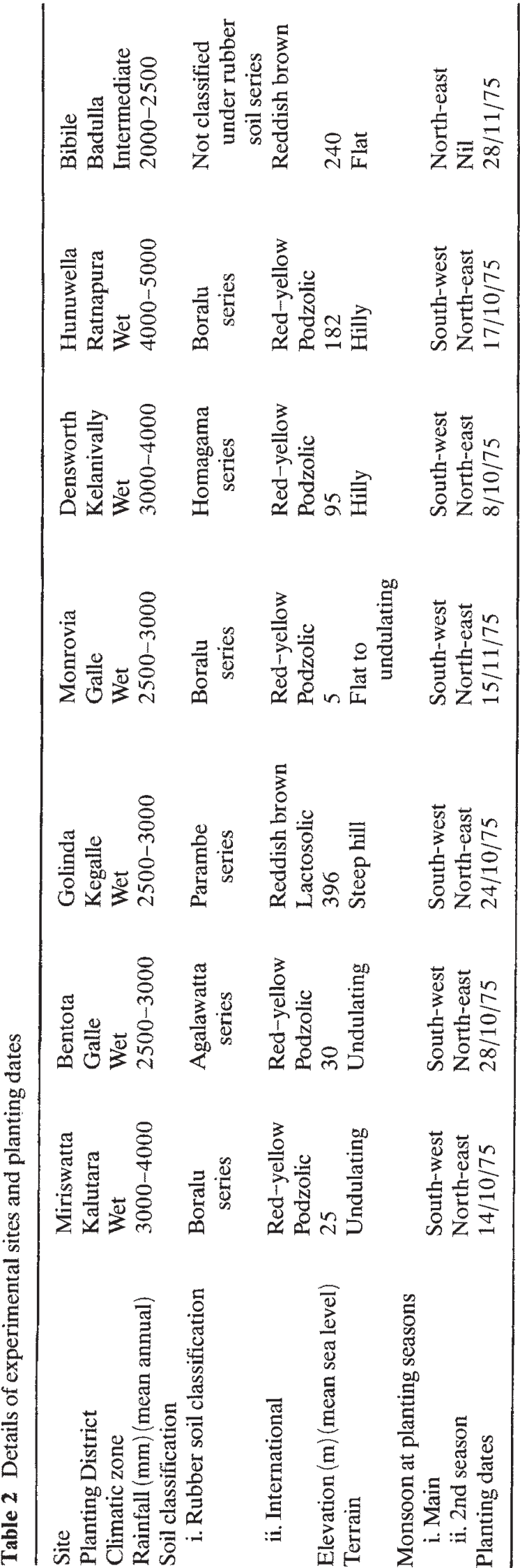

flow stopped, rubber was coagulated in the cup itself by adding 2 per cent formic acid solution and stirring it well. The coagulated rubber in each cup was then made into a 'biscuit' which was washed thoroughly in running water. These were then run, several times, through two smooth rubber rollers to make them into thin rubber laces which were dried in a drying tower for about 20 days, weighed and the dry rubber content for each tree was recorded.

Every year, after 1982, new trees that reached the required girth for tapping were opened for tapping and their yield was also recorded.

\section{Analyses}

All the analyses were performed on individual measurements, pre- and post-tapping girth data being treated separately. In the case of yield data, only those years with six or more test tappings in corresponding months for all sites were analysed.

Firstly, a three-factor analysis of variance (Table 3a) was performed on data collected from all the sites and years. For this analysis, the SAS statistical package was used (SAS/STAT guide for personal computers version 6 edition, 1987).

A two-factor analysis of variance (Table $3 \mathrm{~b}$ ) was also carried out on the same data. In this analysis, data collected from each year were analysed separately. Thus clones and sites were the main sources of variation.

$\mathrm{G}, \mathrm{E}$ and $\mathrm{G} \times \mathrm{E}$ components were estimated treating genotypes and years as statistically fixed effects and sites (environments) as random effects. Years were considered 'fixed' effects in that they represent time of development. Expected mean squares for the threeand two-factor analyses of variance are given in Tables $3 \mathrm{a}$ and $3 \mathrm{~b}$, respectively.

All possible correlations between the nine clone means for girth in different years were calculated giving 105 correlations, each with seven degrees of freedom. Similarly, correlations between mean girth of the nine clones for each pre-tapping year and mean yield over the 5 years were calculated.

\section{Results and discussion}

\section{Girth}

The mean final girths of the nine clones are shown in Table 1. The significant components of the three-factor analysis of variance are tabulated in Table 4 in which it is seen that the second-order interaction and the site $\times$ year interaction were not significant for posttapping girth. 
Table 3 Degrees of freedom (d.f.) and expected mean squares (e.m.s.) for the analyses of variance

\begin{tabular}{lll}
\hline Source & \multicolumn{1}{c}{ d.f. } \\
\hline (a) three-factor analysis of variance & \multicolumn{1}{c}{ e.m.s. } \\
Genotypes $(G)$ & $g-1$ & $\sigma^{2}+n \sigma_{P Y}^{2}$ \\
& & $+n y \sigma_{P}^{2}+n p y \sigma_{G S}^{2}+n p s y K_{G}^{2}$ \\
Sites $(S)$ & $s-1$ & $\sigma^{2}+n \sigma_{P Y}^{2}+n y \sigma_{P}^{2}+n p g y \sigma_{S}^{2}$ \\
Years $(Y)$ & $y-1$ & $\sigma^{2}+n \sigma_{P Y}^{2}+n p g \sigma_{S Y}^{2}+n p g s K_{Y}^{2}$ \\
$G \times S$ & $(g-1)(s-1)$ & $\sigma^{2}+n \sigma_{P Y}^{2}+n y \sigma_{P}^{2}+n p y \sigma_{G S}^{2}$ \\
$G \times Y$ & $(g-1)(y-1)$ & $\sigma^{2}+n \sigma_{P Y}^{2}+n p \sigma_{G S}^{2}+n p s K_{G Y}^{2}$ \\
$S \times Y$ & $(s-1)(y-1)$ & $\sigma^{2}+n \sigma_{P Y}^{2}+n p g \sigma_{S Y}^{2}$ \\
$G \times S \times Y$ & $(g-1)(s-1)(y-1)$ & $\sigma^{2}+n \sigma_{P Y}^{2}+n p \sigma_{G S Y}^{2}$ \\
Plots within $G$ and $S$ & $s g(p-1)$ & $\sigma^{2}+n \sigma_{P Y}^{2}+n y \sigma_{P}^{2}$ \\
$Y \times$ plots within $G$ and & & \\
$S$ & $g s(p-1)(y-1)$ & $\sigma^{2}+n \sigma_{P Y}^{2}$ \\
Within plots & $g s y p(n-1)$ & $\sigma^{2}$ \\
(b) two-factor analysis of variance & \\
Genotypes $(G)$ & $g-1$ & $\sigma^{2}+n \sigma_{P}^{2}+n p \sigma_{G S}^{2}+n p s K_{G}^{2}$ \\
Sites $(S)$ & $s-1$ & $\sigma^{2}+n \sigma_{P}^{2}+n p g \sigma_{S}^{2}$ \\
$G \times S$ & $(g-1)(s-1)$ & $\sigma^{2}+n \sigma_{P}^{2}+n p \sigma_{G S}^{2}$ \\
Plots within $G$ and $S$ & $g s(p-1)$ & $\sigma^{2}+n \sigma_{P}^{2}$ \\
Within plots & $g s p(n-1)$ & $\sigma^{2}$ \\
\end{tabular}

$g=9$ (fixed); $y$ (fixed) $=6$ for pre-tapping girth, 9 for post-tapping girth and 5 for yield; $s=7$ (random); $p=10 ; n=4$ for six sites and 6 for the other site.

Table 4 Estimates of significant variance components $\left(\sigma^{2}\right)$ in the three-factor analysis of variance of girth (see Table 3 for model)

\begin{tabular}{|c|c|c|c|c|c|c|}
\hline \multirow[b]{2}{*}{ Source } & \multicolumn{3}{|c|}{ Pre-tapping } & \multicolumn{3}{|c|}{ Post-tapping } \\
\hline & d.f. & $\sigma^{2}$ & $P$ & d.f. & $\sigma^{2}$ & $P$ \\
\hline Genotypes $(G)$ & 8 & 3.70 & $* * *$ & 8 & 26.25 & $* * *$ \\
\hline $\operatorname{Sites}(S)$ & 6 & 9.27 & $* * *$ & 6 & 12.06 & $* * *$ \\
\hline Years $(Y)$ & 5 & 335.93 & $* * *$ & 8 & 35.95 & $* * *$ \\
\hline$G \times S$ & 48 & 1.41 & $* * *$ & 48 & 2.69 & $* * *$ \\
\hline$G \times Y$ & 40 & 2.98 & $* * *$ & 64 & 3.53 & $* * *$ \\
\hline$S \times Y$ & 30 & 4.12 & $* * *$ & 48 & - & NS \\
\hline$G \times S \times Y$ & 240 & 0.58 & $* * *$ & 384 & - & NS \\
\hline \multicolumn{7}{|l|}{ Plots within } \\
\hline$G$ and $S$ & 560 & 10.05 & $* * *$ & 521 & 29.67 & $* * *$ \\
\hline \multicolumn{7}{|l|}{$Y \times$ plots within } \\
\hline$G$ and $S$ & 2800 & - & NS & 4168 & - & NS \\
\hline Within plots & 8832 & 15.43 & & 9216 & 55.04 & \\
\hline
\end{tabular}

*** $P<0.001$.

To remove the year effect from the analysis and also to study genotypic, environmental (sites) and their interaction effects in more detail, a two-factor analysis of variance was carried out for each year separately. Genotypic, environmental (sites) and genotype $\times$ site interaction variance components for each year were estimated from the two-factor analyses and are pre-
Table 5 Estimates of genotypic, environmental and genotype $\times$ site interaction $(G \times E)$ components for pre(1976-1981) and post-tapping (1982-1990) girth

\begin{tabular}{cccc}
\hline Year & Genotypic & Environmental & $\mathrm{G} \times \mathrm{E}$ \\
\hline 1976 & 0.154 & 0.944 & 0.272 \\
1977 & 0.294 & 1.712 & 0.429 \\
1978 & 1.480 & 6.978 & 1.793 \\
1979 & 5.171 & 19.570 & 3.145 \\
1980 & 10.571 & 20.690 & 4.017 \\
1981 & 16.370 & 20.220 & 4.459 \\
1982 & 15.880 & 19.860 & 3.492 \\
1983 & 18.760 & 25.430 & 3.262 \\
1984 & 21.620 & 19.920 & 5.019 \\
1985 & 26.630 & 16.148 & 5.030 \\
1986 & 32.870 & 13.300 & 4.991 \\
1987 & 39.710 & 15.340 & 6.776 \\
1988 & 47.290 & 8.353 & 7.103 \\
1989 & 49.160 & 6.720 & 6.906 \\
1990 & 52.170 & 8.606 & 8.882 \\
\hline
\end{tabular}

sented in Table 5 separately for pre- and post-tapping girth.

The percentage contributions of these components to the total variation were also estimated and are presented for each year in Fig. 1.

In the first year, the genetic component of girth was only 14 per cent and was the smallest component when 
compared with the other two components: site 67 per cent) and genotype $\times$ site $(19$ per cent). But it can be seen from Fig. 1 that over the years the genetic component gradually increases at the expense of the environment (sites) component and stabilizes at around 75 per cent in the 13th year. The environmental (sites) component which contributed 67 per cent to the total variation in the first year contributed only 13 per cent in the 13 th year after planting.

The genotype $\times$ site interaction component also decreased from 19 per cent in the first year to 12 per cent in the 15th year. This decrease is not consistent, as was found in the other two components, and there are fluctuations over the years. By about the 13th year, the contribution of genotype $\times$ site interaction becomes stabilized at between 11 and 12 per cent.

To explore the possibility of early selection for vigour, the correlations between clones for final $(15 \mathrm{th}$ year) girth with their girth in other years were studied. These correlations are shown graphically in Fig. 2. It can be seen that although the correlation with year 1 is quite high (0.7), it declines to a minimum between years 4 and 5 before rising again reaching 0.8 by year 8 and, thereafter, slowly increasing to almost unity. These correlations show that a fairly reliable early prediction of the 15th year girth could be made by the eighth year and the reliability of the prediction gradually increases from the eighth year onwards. However, the pattern of change in the correlation in early years
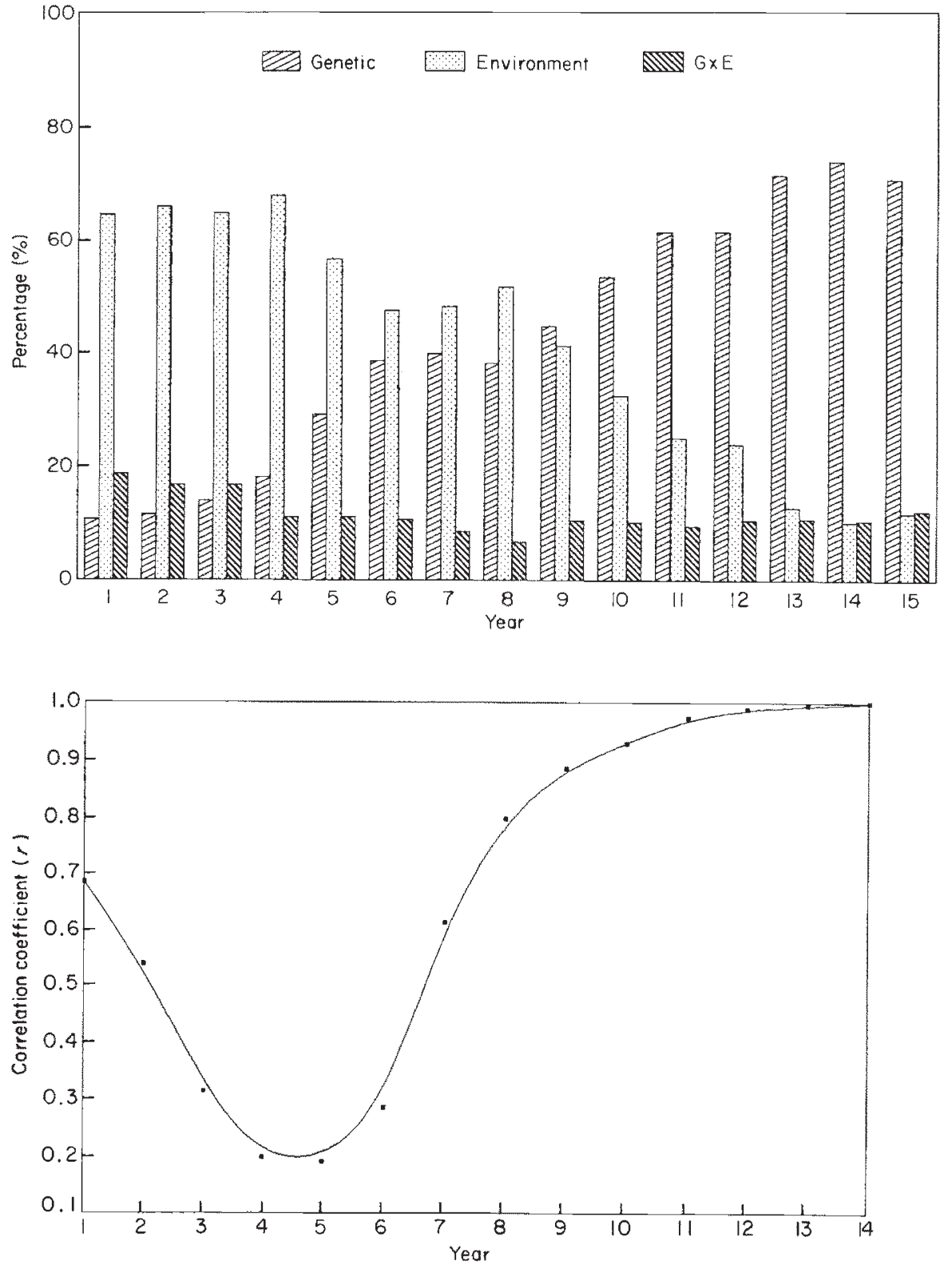

Fig. 1 Change of genetic, environment and genotype-site interaction $(\mathrm{G} \times \mathrm{E})$ components over years for girth.
Fig. 2 Correlation coefficient $(r)$ between year 15 and other years for girth. 
requires explanation. To this end the changes in girth over time were examined (Fig. 3) in several clones (RRIC 102, RRIC 52, RRIM 600 and IAN 45-710). This clearly indicates that the growth behaviour of different clones can change markedly after tapping such that some initially fast growing genotypes may be slower growing, relative to other genotypes, posttapping. This pattern would explain the low correlations with pre-tapping girth, but not the initial decline.

\section{Yield}

The mean annual yields of the nine clones are shown in Table 1.

In the case of yield, all main effects and their interactions, both first- and second-order, turned out to be significant in the three-factor analysis of variance. Significant components have been estimated and are presented in Table 6.

In contrast to girth (Table 4), the year effect is small compared with sites and genotypes.

Two-factor analyses were carried out, separately, on data collected from each year and indicated significant genetic, environmental (sites) and genotype $\times$ site interaction components for all years. The percentage contributions to the total variation by these three components are illustrated in Fig. 4. From Fig. 4 it can be seen that the contributions of genetic and environmental components are more or less the same for all 5 years under consideration, in marked contrast to girth. The genotype $\times$ site interaction component was the smallest component and its contribution was only about half of either of the other two components.

Correlations between annual pre-tapping girth with mean yield (over years) of clones were not significant.
The correlation coefficients had negative signs with the single exception of the correlation of the 1977 mean girth with mean yield. The negative correlation coefficients ranged between -0.4892 and -0.0297 . These results indicate that girth cannot be considered as a good predictor of yield and this is especially true for pre-tapping girth where the correlations were lowest.

This study clearly indicates that there are genetic differences between clones in both yield and vigour. In the very early years, sites are the major influence on the expression of girth but, as the plants age, genetic control increases and by the 13 th or 14 th year genetic effects dominate. Although significant, the effects of $\mathrm{G} \times \mathrm{S}$ within years are minor and decrease with time. This is a surprising result, given the wide range of sites used and emphasizes the over-riding importance of the

Table 6 Estimates of significant variance components $\left(\sigma^{2}\right)$ in the three-factor analysis of variance of yield (see Table 3 for model)

\begin{tabular}{lrrrr}
\hline Source & d.f. & & \multicolumn{1}{c}{$\sigma^{2}$} & $P$ \\
\cline { 1 - 2 } Genotypes $(G)$ & 8 & & 31.73 & $* * * *$ \\
Sites $(S)$ & 6 & & 38.55 & $* * *$ \\
Years $(Y)$ & 4 & 6.20 & $* * *$ \\
$G \times S$ & 48 & & 16.43 & $* * *$ \\
$G \times Y$ & 32 & & 14.69 & $* * *$ \\
$S \times Y$ & 24 & & 7.09 & $* * *$ \\
$G \times S \times Y$ & 192 & & 10.00 & $* * *$ \\
Plots within $G$ and $S$ & 533 & & 39.49 & $* * *$ \\
$Y \times$ plots within $G$ and $S$ & 2132 & - & NS \\
Within plots & 5625 & 102.55 & \\
\cline { 1 - 2 } & & &
\end{tabular}

$* * * P<0.001$.
Fig. 3 Mean girth over years (growth over time).

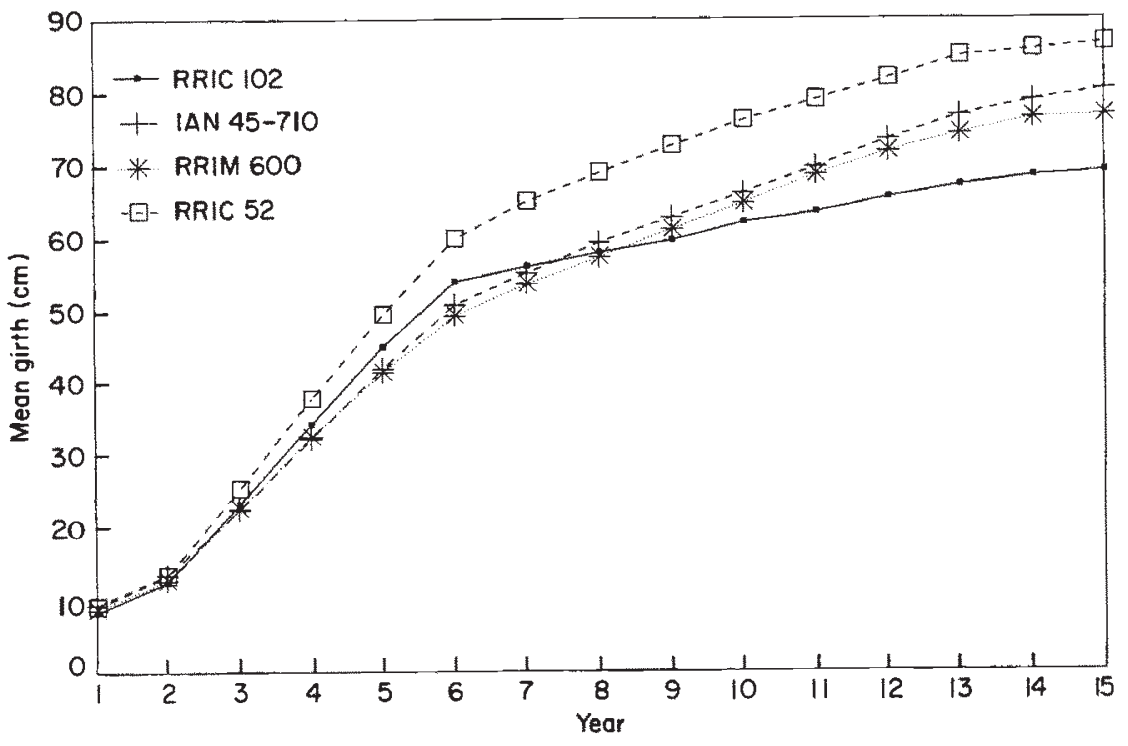




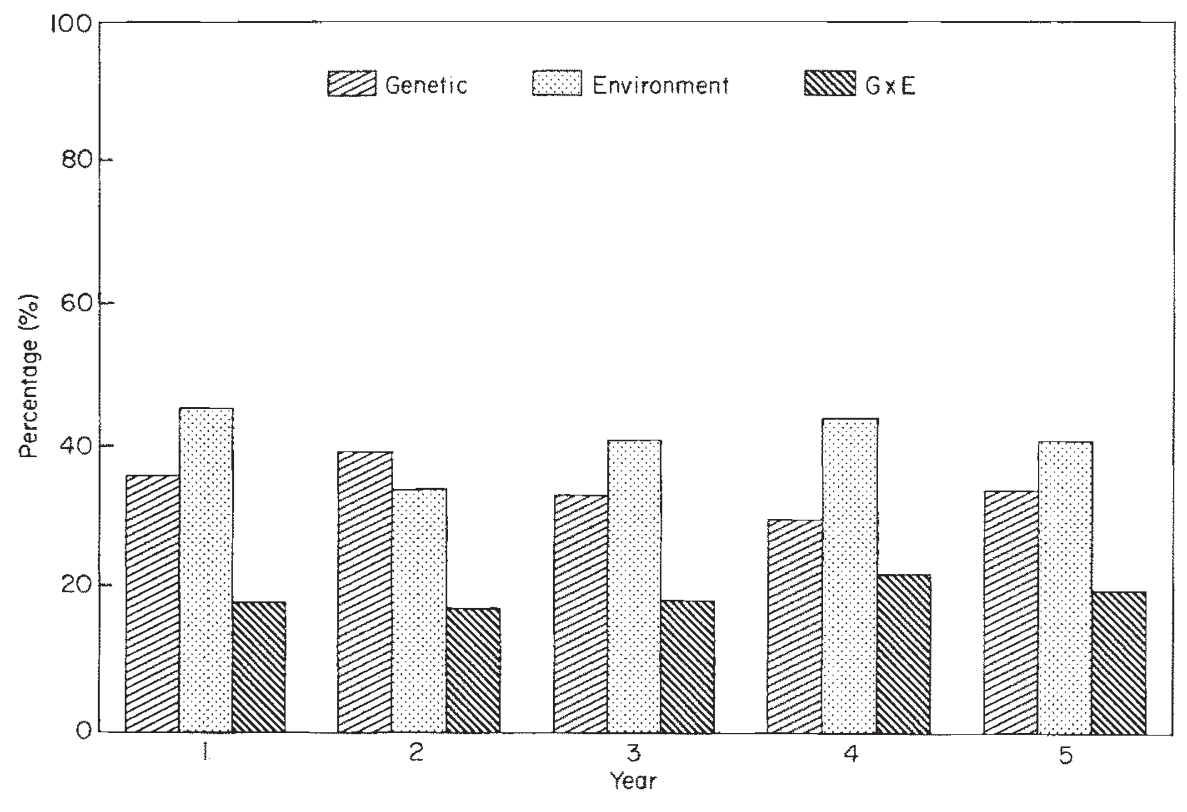

Fig. 4 Change of genetic, environment and genotype-site interaction $(\mathrm{G} \times \mathrm{E})$ components over years for yield. genotype. Correlation analyses between mean girth measurements of different years indicate that early selection for final girth would be possible only from the eighth year after planting. The change in mean girth of different clones over years suggested that the relative growth between clones changes after tapping, i.e. clones which initially grow fast may grow slowly posttapping relative to others. These findings lead to the conclusion that selection for final vigour should be delayed at least until the eighth year from planting.

In the case of yield there was no apparent reversal from environmental to genetical control and the relative importance of $\mathrm{G}, \mathrm{E}$ and $\mathrm{G} \times \mathrm{E}$ remained constant. As only 5 years of yield data have been analysed it is premature to comment on the optimum stage for early prediction for yield. However, the correlation studies indicated that girth cannot be used as an indicator of yield potential of genotypes.

\section{Acknowledgements}

We thank the British Council for financial support, under the Higher Educational Link, to two of us (N.E.M.J. and K.B.K.) to visit the UK to analyse data and prepare it for publication.

\section{References}

ANON. 1991. Plantation Sector Statistical Pocket Book. Published by Ministry of Plantation Industries, Sri Lanka.

JAYASEKERA, N. E. M., SAMARANAYAKE, P. AND KARUNASEKERA, K. B. 1977. Initial studies on the nature of genotype-environment interactions in some Hevea clones. J. Rubber Res. Inst. Sri Lanka, 54, 33-42.

JAYASEKERA, N. E. M. AND KARUNASEKERA, K. B. 1984. Effect of environment on clonal performance with respect to early vigour and yield of Hevea brasiliensis. Proceedings of IRRDB Physiology and Breeding Meeting, Montpellier, France.

SAS/STAT Guide for personal computers version 6 edition. 1987. SAS Institute, Cary, USA.

SILVA, C. G. 1972. Manuring of rubber. RRIC Bull. (New Series), 7, 64-70.

SWAMINATHEN, M. S. 1975. Recent trends in plant breeding. In: RRIM Planters' Bull. No. 141, pp. 136-144.

YOGARATNAM, N., SAMARAPPUL, N. AND HERATH, P. H. M. U. 1992. Status Review Report of the Rubber Research Institute of Sri Lanka: Operational Area. RRISL, Sri Lanka.

YOGARATNAM, N. 1984a. Fertilizers to immature rubber. In: Liyanage, A. de. S. and Peries, O. S. (eds) A Practical Guide to Rubber Planting and Processing, pp. 51-58.

YOGARATNAM, N. 1984 b. Fertilizer to immature rubber. In Liyanage, A. de. S. and Peries, O. S. (eds) A Practical Guide to Rubber Planting and Processing, pp. 104-105. 